\title{
Correction to: A Chromosomal-scale Reference Genome of the Kelp Grouper Epinephelus moara
}

\author{
Qian Zhou ${ }^{1,2} \cdot$ Haoyang Gao ${ }^{3} \cdot H_{a o} X^{1} \cdot$ Haoran Lin $^{4} \cdot$ Songlin Chen ${ }^{1,2}$ (I) \\ Published online: 27 February 2021 \\ ๑) Springer Science+Business Media, LLC, part of Springer Nature 2021
}

\section{Correction to: Marine Biotechnology https://doi.org/10.1007/s10126-020-10003-6}

The original version of this article unfortunately contained a mistake in the References section. The bibliographic details for "Zhou et al. (2020)" should be corrected to:

Zhou Q, Guo X, Huang Y, Gao H, Xu H, Liu S, Zheng W, Zhang TS, Tian CX, Zhu CH, Lin HR, Chen SL (2020) De novo sequencing and chromosomal-scale genome assembly of leopard coral grouper, Plectropomus leopardus. Mol Ecol Resour. https://doi.org/10.1111/1755-0998.13207

The original article has been corrected.
Publisher's Note Springer Nature remains neutral with regard to jurisdictional claims in published maps and institutional affiliations.

The original article can be found online at https://doi.org/10.1007/ s10126-020-10003-6

Haoran Lin

1sslhr@mail.sysu.edu.cn

$\triangle$ Songlin Chen

chensl@ysfri.ac.cn

1 Yellow Sea Fisheries Research Institute, Key Laboratory for Sustainable Development of Marine Fisheries, Ministry of Agriculture, Chinese Academy of Fishery Sciences, Qingdao 266071, China

2 Laboratory for Marine Fisheries Science and Food Production Processes, Qingdao National Laboratory for Marine Science and Technology, Qingdao 266373, China

3 BGI-Qingdao, BGI-Shenzhen, Qingdao 266555, China

4 School of Life Sciences, Sun Yat-Sen University, Guangzhou 510275, China 